\title{
Blood gas analysis of the coronary sinus in patients with heart failure
}

\author{
JIANGHUA ZHANG, CHUNFANG SHAN, YU ZHANG, XIANHUI ZHOU, \\ JINXIN LI, YAODONG LI, QIANG XING and BAOPENG TANG
}

\author{
Department of Cardiology, The First Affiliated Hospital of Xinjiang Medical University, \\ Urmuqi, Xinjiang 830011, P.R. China
}

Received February 4, 2015; Accepted March 6, 2015

DOI: 10.3892/br.2015.446

\begin{abstract}
The difference in cardiac oxygen consumption between individuals with normal cardiac function and those with heart failure (HF), and the association between cardiac oxygen consumption and cardiac ejection fraction (EF) are poorly understood. By establishing a control group composed of individuals with normal cardiac function, the present study aimed to determine the difference in cardiac oxygen consumption between individuals with normal and abnormal cardiac function, as well as the association between cardiac oxygen consumption and cardiac EF. A total of 34 patients with normal cardiac function were enrolled in the control group and 44 patients with HF were enrolled in the experimental group. Blood samples from the aortic root, femoral vein and coronary sinus (CS) were collected from each patient. All the blood samples were subjected to blood gas analysis. The partial pressure of oxygen and oxygen saturation obtained from the peripheral vein and CS of patients with HF were lower than those in patients with normal cardiac function. In each patient with $\mathrm{HF}$, the association between cardiac oxygen consumption and cardiac EF was analyzed using multi-linear correlation and regression analyses. Cardiac oxygen consumption negatively correlated with cardiac EF $(\mathrm{R}=-0.336, \mathrm{P}=0.026)$. Furthermore, linear regression analysis suggested that cardiac EF had a significant effect on cardiac oxygen consumption $(\mathrm{y}=82.906-0.483 \mathrm{x}, \mathrm{P}=0.026)$. In conclusion, myocardial oxygen consumption is greater in individuals with HF compared to those with normal cardiac function. The cardiac EF affects myocardial oxygen consumption in patients with HF.
\end{abstract}

Correspondence to: Mr. Baopeng Tang, Department of Cardiology, The First Affiliated Hospital of Xinjiang Medical University, 137 Liyushan South Road, Urmuqi, Xinjiang 830011, P.R. China E-mail: tangbaopeng@hotmail.com

Key words: heart failure, coronary sinus, blood gas analysis, myocardial oxygen consumption

\section{Introduction}

The coronary sinus (CS) is a small tubular structure just above the posterior left atrioventricular junction and has several main branches $(1,2)$. It accepts blood following myocardial contraction and guides the blood into the right atrium. The blood of the CS contains information that directly or indirectly reflects cardiac metabolism and physical condition $(3,4)$. In heart failure (HF), the information possessed by the CS may be more significant than that possessed by other anatomical locations $(5,6)$.

The results of studies on myocardial oxygen consumption in the setting of different cardiac pathological states have varied (7-9). HF increases myocardial oxygen consumption. Therefore, the blood in the CS has a lower oxygen saturation $\left(\mathrm{SO}_{2}\right)$ in the setting of worsening cardiac function (10). Blood gas analysis results from the CS indirectly reflect myocardial oxygen consumption. The association between cardiac oxygen consumption and cardiac ejection fraction (EF) has not been definitively elucidated by previous studies and control groups composed of patients with normal cardiac function have been absent from these studies. By establishing a control group, the present study aimed to determine the difference in cardiac oxygen consumption between patients with normal cardiac function and patients with abnormal cardiac function, and identify the association between myocardial oxygen consumption and $\mathrm{EF}$.

\section{Patients and methods}

Patients. Between June 2013 and December 2013, 78 patients met the inclusion criteria of the study, signed an informed consent form and were subsequently included in the study. Of these patients, 34 had normal cardiac function and were placed in the control group and 44 had abnormal cardiac function and were placed in the experimental group. The inclusion criteria for the experimental group were as follows: Cardiomyopathy; a left ventricular $\mathrm{EF}$ (LVEF) $<50 \%$; a history of $\mathrm{HF}>6$ months; New York Heart Association (NYHA) stage $\geq$ II; and agreement by the patient to provide blood samples from the CS, aortic root and peripheral vein. The exclusion criteria for the experimental group were as follows: Absence of cardiopathy; a LVEF $\geq 50 \%$; and refusal of the patient to provide blood 
samples from the CS, aortic root and peripheral vein. The inclusion criteria of the control group were as follows: LVEF $\geq 50 \%$ and agreement by the patient to provide blood samples from the CS, aortic root and peripheral vein. The exclusion criteria for the control group were as follows: LVEF $<50 \%$; a history of HF; a history of myocardial infarction or disease causing increased myocardial oxygen consumption (hyperthyroidism and anemia); and refusal of the patient to provide blood samples from the CS, aortic root and peripheral vein. The experimental group consisted of 31 males and 13 females. The control group consisted of 16 males and 18 females. The average ages of the individuals in the experimental and control group were $60.27 \pm 10.65$ and $54.97 \pm 11.96$ years, respectively. The experimental group included older patients and a greater proportion of male patients. Baseline information for the two groups is shown in Table I.

Method of extracting blood samples. All the patients were prepared to undergo either coronary angiography or radiofrequency catheter ablation. Two sheathes were placed in the femoral artery and femoral vein and blood samples were extracted from the aortic root, CS and femoral vein using a coronary angiographic catheter. All the patients with HF were treated with anti-HF drugs and their cardiac function improved to a classification of NYHA II. Prior to extracting blood from the $\mathrm{CS}$, the $\mathrm{X}$-ray position was $30^{\circ}$ relative to the left anterior oblique position. Under fluoroscopy, the catheter reached the upper right atrium and turned toward the spine. Subsequently, the operator slowly pulled back the catheter. Jumping of the catheter signified that the catheter's tip had potentially reached the CS. The operator used a contrast agent during angiography to ensure that the catheter was within the CS.

Blood gas analysis. Following the withdrawal of blood samples from three different places, the samples were twice subjected to blood gas analysis. The result of each blood gas analysis is expressed as an average number. The machine used for blood gas analysis was the Abbott i-STAT EG7+ (Abbott, Abbott Park, IL, USA).

Statistical analysis. Statistical analyses were performed using SPSS 17.0 (SPSS, Inc., Chicago, IL, USA). Continuous variables were expressed as the mean \pm standard deviation and analyzed using independent sample t-tests. Correlation analyses and regression analyses were also performed. $\mathrm{P}<0.05$ was considered to indicate a statistically significant difference.

\section{Results}

Patients. As each of the groups had a different pathophysiological baseline, each group's baseline information was different. The experimental group included patients with HF and was older and consisted of more males than the control group. The major diseases characterizing the experimental group were ischemic cardiomyopathy and dilated cardiomyopathy. By contrast, the major diseases of the control group were arrhythmia and coronary heart disease, but not myocardial infarction. Additionally, five healthy patients were enrolled in the control group as they were suspected
Table I. Baseline characteristics.

\begin{tabular}{|c|c|c|c|}
\hline Characteristics & $\begin{array}{l}\text { Experimental } \\
\text { group }\end{array}$ & $\begin{array}{l}\text { Control } \\
\text { group }\end{array}$ & P-value \\
\hline Number & 44 & 34 & \\
\hline Gender, m/f & $31 / 13$ & $16 / 18$ & $<0.001$ \\
\hline Age, years & $60.27 \pm 10.65$ & $54.97 \pm 11.96$ & $<0.001$ \\
\hline DCM, n & 14 & 0 & \\
\hline ICM, n & 24 & 0 & \\
\hline HCM, n & 4 & 0 & \\
\hline VDH, n & 2 & 0 & \\
\hline PSVT, n & 0 & 17 & \\
\hline RVOT, n & 0 & 2 & \\
\hline $\mathrm{CHD}, \mathrm{n}$ & 24 & 9 & \\
\hline $\mathrm{PE}, \mathrm{n}$ & 0 & 5 & \\
\hline $\mathrm{HP}, \mathrm{n}$ & 18 & 12 & \\
\hline $\mathrm{DM}, \mathrm{n}$ & 12 & 4 & \\
\hline $\mathrm{AF}, \mathrm{n}$ & 6 & 1 & \\
\hline $\begin{array}{l}\text { History of HF, } \\
\text { years }\end{array}$ & $2.49 \pm 3.22$ & 0 & \\
\hline SBP, mmHg & $118.82 \pm 21.26$ & $126.59 \pm 14.47$ & 0.710 \\
\hline $\mathrm{DBP}, \mathrm{mmHg}$ & $73.41 \pm 14.21$ & $76.71 \pm 10.79$ & 0.264 \\
\hline Weight, kg & $70.68 \pm 13.15$ & $70.38 \pm 16.43$ & 0.299 \\
\hline $\mathrm{HB}, \mathrm{g} / \mathrm{l}$ & $134.02 \pm 17.31$ & $137.88 \pm 16.47$ & 0.322 \\
\hline $\mathrm{CR}, \mathrm{mmol} / \mathrm{l}$ & $89.55 \pm 25.28$ & $63.97 \pm 15.19$ & $<0.001$ \\
\hline ALT, U & $29.26 \pm 20.77$ & $29.23 \pm 21.07$ & 0.994 \\
\hline CK-MB & $15.52 \pm 9.44$ & $13.37 \pm 4.96$ & 0.233 \\
\hline LVED, mm & $62.64 \pm 7.97$ & $47.71 \pm 3.24$ & $<0.001$ \\
\hline $\mathrm{LAD}, \mathrm{mm}$ & $42.30 \pm 4.69$ & $33.68 \pm 4.33$ & $<0.001$ \\
\hline $\mathrm{EF}, \%$ & $39.25 \pm 5.67$ & $63.21 \pm 4.63$ & $<0.001$ \\
\hline
\end{tabular}

DCM, dilated cardiomyopathy; ICM, ischemic cardiomyopathy; HCM, hypertensive cardiomyopathy; VDH, valvular heart disease; PSVT, paroxysmal supraventricular tachycardia; RVOT, right ventricular outflow tract; CHD, coronary heart disease; PE, physical examination; HP, hypertension; DM, diabetes mellitus; $\mathrm{AF}$, atrial fibrillation; HF, heart failure; SBP, systolic blood pressure; DBP, diastolic blood pressure; HB, hemoglobin; CR, creatinine; ALT, alanine aminotransferase; CK-MB, creatine kinase isoenzyme; LVED, left ventricular end diastolic diameter; LAD, left atrial diameter; EF, ejection fraction; $\mathrm{m}$, male; $\mathrm{f}$, female.

of having coronary artery disease and required a coronary angiogram to determine their diagnoses. Due to cardiac dysfunction, the experimental group had poor kidney function, larger left ventricular end diastolic diameters and larger left atrial sizes. However, the blood pressures, weights, hemoglobin values and liver function test results of the two groups were not significantly different. All the clinical data are shown in Table I.

Blood gas analysis. The partial pressure of oxygen $\left(\mathrm{PO}_{2}\right)$ and $\mathrm{SO}_{2}$ in the peripheral veins of the experimental group were lower than those in the control group. Similar results were obtained for the CS, as the $\mathrm{PO}_{2}$ and $\mathrm{SO}_{2}$ of the CSs of the experimental group were also lower than those in the control group. The blood 
Table II. Blood gas analysis results.

\begin{tabular}{|c|c|c|c|}
\hline Characteristics & $\begin{array}{l}\text { Experimental } \\
\text { group }\end{array}$ & $\begin{array}{l}\text { Control } \\
\text { group }\end{array}$ & P-value \\
\hline $\mathrm{pH}(\mathrm{A})$ & $7.41 \pm 0.45$ & $7.40 \pm 0.434$ & 0.368 \\
\hline $\mathrm{PCO}_{2}(\mathrm{~A}), \mathrm{mmHg}$ & $34.98 \pm 4.84$ & $37.92 \pm 5.05$ & 0.011 \\
\hline $\mathrm{PO}_{2}(\mathrm{~A}), \mathrm{mmHg}$ & $68.73 \pm 11.06$ & $70.26 \pm 11.43$ & 0.550 \\
\hline $\mathrm{SO}_{2}(\mathrm{~A}), \%$ & $93.09 \pm 2.93$ & $93.35 \pm 3.20$ & 0.708 \\
\hline $\mathrm{BE}(\mathrm{A}), \mathrm{mmol} / \mathrm{l}$ & $-2.48 \pm 3.22$ & $-1.21 \pm 2.33$ & 0.056 \\
\hline $\mathrm{HCO}_{3-}(\mathrm{A}), \mathrm{mmol} / \mathrm{l}$ & $22.08 \pm 2.99$ & $23.29 \pm 2.28$ & 0.054 \\
\hline $\mathrm{pH}(\mathrm{V})$ & $7.37 \pm 0.38$ & $7.38 \pm 0.27$ & 0.079 \\
\hline $\mathrm{PCO}_{2}(\mathrm{~V}), \mathrm{mmHg}$ & $44.29 \pm 6.27$ & $42.06 \pm 5.54$ & 0.106 \\
\hline $\mathrm{PO}_{2}(\mathrm{~V}), \mathrm{mmHg}$ & $31.57 \pm 5.12$ & $34.76 \pm 6.33$ & 0.016 \\
\hline $\mathrm{SO}_{2}(\mathrm{~V}), \%$ & $56.98 \pm 11.73$ & $63.44 \pm 11.85$ & 0.019 \\
\hline $\mathrm{BE}(\mathrm{V}), \mathrm{mmol} / \mathrm{l}$ & $-0.20 \pm 3.12$ & $0.00 \pm 2.82$ & 0.766 \\
\hline $\mathrm{HCO}_{3}^{-}(\mathrm{V}), \mathrm{mmol} / \mathrm{l}$ & $25.16 \pm 2.96$ & $25.13 \pm 2.73$ & 0.959 \\
\hline $\mathrm{pH}(\mathrm{CS})$ & $7.35 \pm 0.63$ & $7.36 \pm 0.40$ & 0.445 \\
\hline $\mathrm{PCO}_{2}(\mathrm{CS}), \mathrm{mmHg}$ & $48.25 \pm 6.66$ & $47.89 \pm 5.48$ & 0.079 \\
\hline $\mathrm{PO}_{2}(\mathrm{CS}), \mathrm{mmHg}$ & $20.20 \pm 3.43$ & $24.18 \pm 3.25$ & $<0.001$ \\
\hline $\mathrm{SO}_{2}(\mathrm{CS}), \%$ & $29.16 \pm 7.33$ & $35.76 \pm 7.60$ & $<0.001$ \\
\hline $\mathrm{BE}(\mathrm{CS}), \mathrm{mmol} / \mathrm{l}$ & $1.18 \pm 3.39$ & $1.88 \pm 2.97$ & 0.382 \\
\hline $\mathrm{HCO}_{3-}(\mathrm{CS}), \mathrm{mmol} / \mathrm{l}$ & $27.12 \pm 3.31$ & $27.24 \pm 2.71$ & 0.863 \\
\hline $\mathrm{SO}_{2}(\mathrm{~A}-\mathrm{CS}), \mathrm{mmol} / \mathrm{l}$ & $63.93 \pm 8.16$ & $57.58 \pm 7.44$ & 0.001 \\
\hline
\end{tabular}

$\mathrm{A}$, artery; $\mathrm{V}$, vein; $\mathrm{CS}$, coronary sinus; $\mathrm{pH}$, potential of hydrogen; $\mathrm{PCO}_{2}$, pressure of carbon dioxide; $\mathrm{PO}_{2}$, pressure of oxygen; $\mathrm{SO}_{2}$, oxygen saturation; $\mathrm{BE}$, base excess.

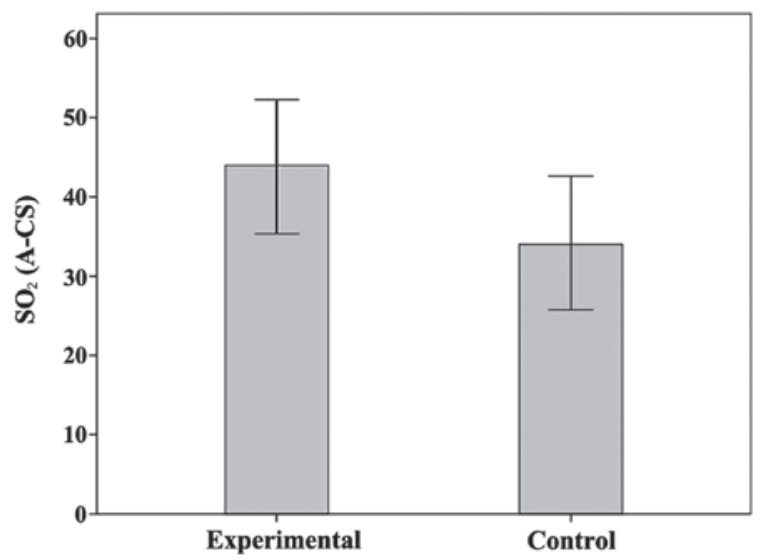

Figure 1. Difference between aortic root and coronary sinus.

within the coronary artery was derived from the aortic root. As a result, the blood gas analysis of the coronary artery yielded results similar to those of the aortic root. The coronary artery and CS are the sole cardiac arterial and venous blood supply. Therefore, the blood flow volume of the coronary artery should be the same as the blood flow volume of the CS. Therefore, the $\mathrm{SO}_{2}$ difference was used between the aortic root and the CS to represent myocardial oxygen consumption. Myocardial oxygen consumption in patients with HF is greater than that in patients without HF. The detailed results of the blood gas analyses are shown in Table II and Fig. 1.

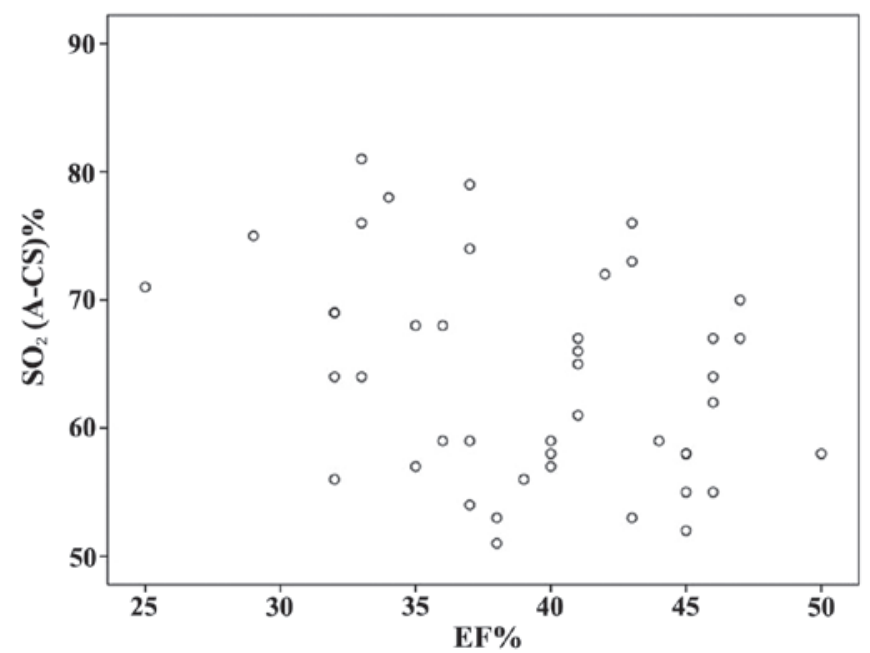

Figure 2. Scatter diagram of cardiac ejection fraction (EF) and oxygen saturation $\left(\mathrm{SO}_{2}\right)$ [aortic root and coronary sinus (A-CS)]

Correlation and regression analysis. Using linear correlation analysis, the association between cardiac EF and myocardial oxygen consumption was examined in the experimental group. There is a significant correlation between cardiac EF and myocardial oxygen consumption $(\mathrm{R}=-0.336, \mathrm{P}=0.026)$. The association between cardiac EF and cardiac oxygen consumption was also examined using linear regression analysis. The F value of the regression model was $5.333(\mathrm{P}=0.026)$, indicating statistical significance. The scatter diagram depicting $\mathrm{SO}_{2}$ and EF is shown in Fig. 2. The correlation between cardiac EF and myocardial oxygen consumption was statistically significant. The regression equation was $y=82.906-0.483 x$. Thus, cardiac EF not only correlates with cardiac oxygen consumption, but is also likely to influence myocardial oxygen consumption.

\section{Discussion}

Previous studies have suggested that arterial $\mathrm{SO}_{2}$ is associated with mortality and rehospitalization, and has prognostic implications for patients with $\mathrm{HF}(11,12)$. These studies demonstrated that lower arterial $\mathrm{SO}_{2}$ indicates a worse prognosis. Arterial $\mathrm{SO}_{2}$ reflects the body's supply of oxygen; however, it does not reflect cardiac oxygen consumption. Therefore, to a certain degree, this conclusion is controversial (13).

The CS contains only venous blood as a result of cardiac metabolism. The $\mathrm{SO}_{2}$ of the blood is the result of myocardial oxygen consumption. Therefore, the difference in $\mathrm{SO}_{2}$ between the aortic root and CS can be used to represent myocardial oxygen consumption. The difference directly reflects myocardial oxygen consumption.

A previous study has shown that worsening cardiac function is associated with lower $\mathrm{CS} \mathrm{SO}_{2}$ (10). However, few investigations of blood gas in the CS have featured a control group composed of patients with normal cardiac function. In the present study, by comparing patients with normal cardiac function with those with abnormal function, patients with abnormal cardiac function have a lower $\mathrm{SO}_{2}$ and $\mathrm{PO}_{2}$ in the peripheral vein and CS. Previous studies have suggested that the body's oxygen consumption may increase in the setting of $\mathrm{HF}$ and is an independent predicator of mortality due to 
HF $(14,15)$. The results of the present study indicate that myocardial oxygen metabolism is similar to the body's oxygen metabolism in the setting of HF. A conclusion regarding the association between myocardial oxygen consumption and the prognosis of HF was not achieved due to an insufficient time to reach an endpoint.

Previous studies have suggested that $\mathrm{CS} \mathrm{SO}_{2}$ and $\mathrm{PO}_{2}$ levels are associated with cardiac function and the prognosis of patients with HF is associated with the oxygen content of CS blood $(10,16)$. However, Boehrer et al (17) disagreed with these results. In their study, the content of the CS was not associated with the extent of coronary artery disease or left ventricular dysfunction. In the present study, it was found via correlation and regression analyses that cardiac EF and myocardial oxygen consumption have a linear association, as well as that cardiac EF influences myocardial oxygen consumption. A significant correlation index $(\mathrm{R}),-0.336$, was obtained from the data. However, this correlation index is relatively small, indicating that the correlation is not extremely strong and indicates that there are other factors that impact myocardial oxygen consumption, such as medications, autonomic nervous tension and physical functions (18-20). Compared with other unstable factors, cardiac EF may be the most stable factor that influences myocardial oxygen consumption in patients with HF.

Certain limitations of the present study should be considered. First, the members of the control group were not completely healthy. Although patients in the control group had normal cardiac function, preexisting diseases in the group, such as arrhythmia and coronary artery disease, may have had an effect on myocardial oxygen consumption $(9,21)$. Additionally, as no follow-up occurred with the experimental group, whether myocardial oxygen consumption is a significant prognostic indicator of HF was not determined.

In the present study, myocardial oxygen consumption in individuals with HF was greater compared to those with normal cardiac function. Cardiac EF is associated with myocardial oxygen consumption and influences myocardial oxygen consumption. More studies are required to determine whether myocardial oxygen consumption can predict the prognosis of $\mathrm{HF}$.

\section{References}

1. Serova EV: Surgical anatomy of the coronary venous sinus. Grudn Khir 5: 24-26, 1963 (In Russian).

2. Gilard M, Mansourati J, Etienne Y, Larlet JM, Truong B, Boschat J and Blanc JJ: Angiographic anatomy of the coronary sinus and its tributaries. Pacing Clin Electrophysiol 21: 2280-2284, 1998.

3. Kagaya Y, Otani H, Tanikawa T, Namiuchi S, Isoyama S and Shirato K: Concentrations of angiotensin II, endothelin-1 and BNP in the coronary sinus and ascending aorta of patients with heart disease. Heart 81: 102-103, 1999.

4. Yasuda T, Sawa S, Ishikawa N and Tanaka N: Simultaneous measurement of coronary sinus oxygen saturation and blood flow during terminal warm blood cardioplegia in coronary artery bypass grafting. Ann Thorac Cardiovasc Surg 4: 271-274, 1998.

5. Tsutamoto T, Sakai H, Nishiyama K, Tanaka T, Fujii M, Yamamoto $\mathrm{T}$ and Horie M: Direct comparison of transcardiac increase in brain natriuretic peptide (BNP) and N-terminal proBNP and prognosis in patients with chronic heart failure. Circ J 71: 1873-1878, 2007.
6. Watson CJ, Ledwidge MT, Phelan D, Collier P, Byrne JC, Dunn MJ, McDonald KM and Baugh JA: Proteomic analysis of coronary sinus serum reveals leucine-rich $\alpha 2$-glycoprotein as a novel biomarker of ventricular dysfunction and heart failure. Circ Heart Fail 4: 188-197, 2011.

7. Vlasov IuA and Okuneva GN: Specific oxygen consumption in the myocardium of patients with congenital and acquired heart defects. Fiziol Cheloveka 29: 133-137, 2003 (In Russian).

8. Vlasov IuA, Okuneva GN, Litasova EE and Nikolaeva TM: Correlation between specific oxygen consumption in the myocardium and myocardial mass in healthy people and in patients with heart defects. Fiziol Cheloveka 21: 92-99, 1995 (In Russian).

9. Kumon K, Kuwabara M, Hirata T, Tanaka K, Kawazoe K, Kitoh Y, Nakajima N and Fujita T: Continuous measurement of coronary sinus oxygen saturation after cardiac surgery. Crit Care Med 15: 595-597, 1987.

10. White M, Rouleau JL, Ruddy TD, De Marco T, Moher D and Chatterjee K: Decreased coronary sinus oxygen content: A predictor of adverse prognosis in patients with severe congestive heart failure. J Am Coll Cardiol 18: 1631-1637, 1991.

11. Milo-Cotter O, Cotter G, Kaluski E, Rund MM, Felker GM, Adams KF, O'Connor CM and Weatherley BD: Rapid clinical assessment of patients with acute heart failure: First blood pressure and oxygen saturation - is that all we need? Cardiology 114: 75-82, 2009.

12. Masip J, Gayà M, Páez J, Betbesé A, Vecilla F, Manresa R and Ruíz P: Pulse oximetry in the diagnosis of acute heart failure. Rev Esp Cardiol (Engl Ed) 65: 879-884, 2012.

13. Miñana G, Núñez J, Bañuls P, Sanchis J, Núñez E, Robles R, Mascarell B, Palau P, Chorro FJ and Llàcer A: Prognostic implications of arterial blood gases in acute decompensated heart failure. Eur J Intern Med 22: 489-494, 2011.

14. van den Broek SA, van Veldhuisen DJ, de Graeff PA, Landsman ML, Hillege $\mathrm{H}$ and Lie KI: Comparison between New York Heart Association classification and peak oxygen consumption in the assessment of functional status and prognosis in patients with mild to moderate chronic congestive heart failure secondary to either ischemic or idiopathic dilated cardiomyopathy. Am J Cardiol 70: 359-363, 1992.

15. Cohn JN, Johnson GR, Shabetai R, Loeb H, Tristani F, Rector T, Smith R and Fletcher R: Ejection fraction, peak exercise oxygen consumption, cardiothoracic ratio, ventricular arrhythmias and plasma norepinephrine as determinants of prognosis in heart failure. The V-HeFT VA Cooperative Studies Group. Circulation 87 (Suppl 6): VI5-V16, 1993.

16. Foëx P and Ryder WA: Effect of $\mathrm{CO}_{2}$ on the systemic and coronary circulations and on coronary sinus blood gas tensions. Bull Eur Physiopathol Respir 15: 625-638, 1979.

17. Boehrer JD, Lange RA, Willard JE and Hillis LD: Lack of relation of coronary sinus oxygen content to extent of coronary artery disease or left ventricular dysfunction. Am J Cardiol 70: 1623-1625, 1992

18. Hagl S, Froer W, Heimisch W, Braun E, Gebhardt K and Mendler N: The effect of nitrates on the function of intact and ischemic myocardium (author's transl). Thoraxchir Vask Chir 25: 219-229, 1977 (In German).

19. Kumakura S and Oshima T: Effects of beta blockers on cardiac function and myocardial oxygen consumption in the isolated supported heart preparation of the dog. Jpn Heart J 16: 592-602, 1975.

20. Alders DJ, Cornelussen RN, Prinzen FW, Specht PA, Noble MI, Drake-Holland AJ, de Kanter FJ and van Beek JH: Regional sympathetic denervation affects the relation between canine local myocardial blood flow and oxygen consumption. Exp Physiol 92: 541-548, 2007.

21. Miwa K, Fujita M, Ejiri M and Sasayama S: Biphasic changes (initial increase and late decrease) in coronary sinus venous oxygen saturation during anginal attacks induced by intracoronary acetylcholine in patients with variant angina. Cardiology 81: 221-232, 1992. 